\title{
QUALIDADE MICROBIOLÓGICA E PARÂMETROS FÍSICO-QUÍMICOS DA ÁGUA EM UMA PROPRIEDADE RURAL COM BOVINOCULTURA
}

\author{
MARTINS, Heytor Lemos ${ }^{1}$ \\ MARTINS, Eduardo da Silva ${ }^{2}$ \\ MILLAN, Rodrigo Ney ${ }^{3}$ \\ GUIDASTRE, Fernanda Cassia ${ }^{4}$ \\ RIBEIRO, Otavio Martins ${ }^{5}$
}

\begin{abstract}
RESUMO: A criação de gado próximo a corpos hídricos é um importante fator de interferência na qualidade da água. Esses recursos hídricos são utilizados para diversas atividades dentro da propriedade rural, dentre elas a dessedentação animal. O presente trabalho teve como objetivo avaliar os impactos causados por criação de bovinos em relação à água de rios de primeira ordem utilizada em uma propriedade rural de pequeno porte do município de Frutal,MG (2002'29"S 48 51'53"O). O estudo foi conduzido em uma propriedade rural com criação de bovinos próxima ao leito do rio, utilizado para dessedentação animal e irrigação de hortaliças. Foram realizadas análises microbiológicas, parâmetros físico-químicos e nutrientes. Observou-se que a presença de coliformes termotolerantes e a turbidez foram os parâmetros mais impactados pela presença do gado. Foi observado também que a água estava com concentração muito acima da permitida em relação à concentração de Fósforo total, antes e após o contato com o gado, fato este que pode estar relacionado ao tipo de solo ou então às atividades agrícolas subjacentes, com incremento de fosfatos. A água estava dentro dos padrões para os demais parâmetros avaliados. O estudo mostra a necessidade de conter o contato livre do gado ao curso d'água, visando prevenir a contaminação da água utilizada na irrigação das hortaliças e possíveis doenças que possam ser veiculadas.
\end{abstract}

Palavras-chave: Pecuária, Sistema lótico, Qualidade de água, Avaliação.

\section{MICROBIOLOGICAL QUALITY AND PHYSICO-CHEMICAL PARAMETERS OF WATER IN A RURAL PROPERTY WITH BOVINOCULTURE}

SUMMARY: Cattle farming close to water resources is an important factor in interfering with water quality. These water resources are used for various activities within the rural property, among them animal drinking. The present work aimed to evaluate the impacts caused by cattle breeding in relation to the water of first order rivers used in a small rural property in the municipality of Frutal MG $\left(20^{\circ} 02^{\prime} 29^{\prime \prime} \mathrm{S} 48^{\circ} 51^{\prime} 53^{\prime \prime} \mathrm{W}\right)$. The study was conducted on a rural property with cattle rearing close to the riverbed, used for animal feed and vegetable irrigation. Microbiological analyzes, physical-chemical parameters and nutrients were performed. It was observed that the presence of thermotolerant coliforms and turbidity were the parameters most impacted by the presence of cattle. It was also observed that the water was with a concentration far above that allowed in relation to the concentration of total phosphorus, before and after contact with cattle, a fact that may be related to the type of soil or to the underlying agricultural activities, with an increase of phosphates. The water was within the standards for the other parameters evaluated. The study shows the need to contain free contact of cattle to the watercourse, in order to prevent contamination of the water used in the irrigation of vegetables and possible diseases that can be transmitted.

Keywords: Livestock, Lotic system, Water quality, Evaluation.

\section{INTRODUÇÃO}

A água é um recurso natural indispensável à vida, essencial à produção de alimentos, desenvolvimento econômico e promoção social. Porém, a água com má qualidade pode trazer riscos à saúde, atuando como veículo para vários agentes biológicos e químicos. No meio rural,

\footnotetext{
${ }^{1}$ Mestrando em Ciências Ambientais. Universidade do Estado de Minas Gerais, unidade Frutal.

${ }^{2}$ Professor Doutor. Universidade do Estado de Minas Gerais, unidade Frutal.

${ }^{3}$ Professor Doutor. Universidade do Estado de Minas Gerais, unidade Frutal.

${ }^{4}$ Licenciada e Bacharel em Química. Universidade do Estado de Minas Gerais, unidade Frutal.

${ }^{5}$ Bolsista BIC Jr. Escola Estadual Lauriston Souza, Frutal.
} 
dentre as possíveis fontes de poluição que tornam a água imprópria ao consumo, destacam-se as atividades agropecuárias, que podem provocar contaminação dos aquíferos com a presença de fezes de animais, substâncias inorgânicas (inseticidas, fungicidas, herbicidas e fertilizantes), lançamento inadequado de esgoto doméstico e manutenção inapropriada de cisternas, dentre outros fatores (KASELANI, 2017; BORTOLLI et al., 2018).

Para avaliar a qualidade da água, podem ser utilizadas variáveis físico-químicas como $\mathrm{pH}$, temperatura, oxigênio dissolvido, turbidez, potencial de oxirredução, sólidos totais solúveis e condutividade elétrica, e variáveis microbiológicas como os coliformes termotolerantes e nutrientes, cujos padrões são estabelecidos pela normativa do Conselho Nacional de Meio Ambiente (CONAMA) resolução 357/2005 (BRASIL, 2005).

Com relação à indicadores biológicos, um dos principais é o grupo dos coliformes termotolerantes, que apontam presença de contaminação fecal na água, o que pode trazer outros tipos de contaminantes e, consequentemente, riscos à saúde do consumidor (SCURACCHIO, 2010). Segundo o Standard Methods for the Examination of Water and Wastewater coliformes são "todas as bactérias aeróbias ou anaeróbias facultativas, gram negativas, não esporuladas e na forma de bastonete", as quais fermentam a lactose com formação de gás dentro de $48 \mathrm{~h}$ a $35^{\circ} \mathrm{C}$ (coliformes totais) ou a $44,5^{\circ} \mathrm{C}$ (coliformes termotolerantes ou fecais) (APHA, 2012).

Dados revelam que milhões de pessoas, principalmente crianças, morrem anualmente por doenças relacionadas à água no mundo todo. Dentre estas doenças de veiculação hídrica, a contaminação bacteriana pode contribuir para a transmissão de diversas doenças, tais como cólera, salmonelose, shiguelose e gastrenterites causadas por Escherichia coli diarreiogênica, especialmente em crianças e imucomprometidos, fato que resulta em ônus para os países em desenvolvimento (BURGOS et al., 2014).

Além de ser um importante veículo de transmissão de agentes patogênicos, a água pode ser também uma fonte de contaminação por produtos químicos, com destaque para substâncias oriundas de atividades agrícolas (que podem provocar contaminação dos aquíferos com substâncias inorgânicas como inseticidas, fungicidas, herbicidas e fertilizantes) e o lançamento inadequado de efluentes doméstico e/ou industrial (SILVA, ARAÚJO, 2008; GROTT et al., 2016; BORTOLLI et al., 2018).

O risco de ocorrência de surtos de doenças veiculadas pela água é alto no meio rural, devido à facilidade de contaminação bacteriana de águas captadas em fontes de abastecimento superficial, muitas vezes próximas de fontes contaminadoras como fossas e áreas de pastagens com a presença de animais. Desse modo, o uso do solo e da água pelas atividades agrícolas e 
pecuárias deve ser acompanhado de modo a manter a integridade do solo e a qualidade de água. (VALIAS et al., 2002; TIECHER, 2017).

Diante deste contexto, é fundamental que se conheça a qualidade da água utilizada nas propriedades, em seus diferentes usos, especialmente naqueles relacionados à irrigação, consumo direto para o homem e dessedentação animal nas propriedades. Assim, o presente trabalho teve como objetivo avaliar a qualidade da água de um rio de primeira ordem em uma propriedade rural de pequeno porte com criação de bovinos próxima ao leito do rio. A hipótese é de que a criação de bovinos próximo ao leito do rio afeta a qualidade da água utilizada para a irrigação de hortaliças na propriedade.

\section{METODOLOGIA}

\section{1 Área de estudo}

$\mathrm{O}$ experimento foi realizado em uma propriedade rural de pequeno porte localizada próximo ao município de Frutal-MG, com aproximadamente 43,8 ha de área total, sendo 0,85 ha da sede, horta e plantio para consumo, e o restante dividido entre pastagem com gado e área de proteção permanente (APP) (Figura 1).

Figura 1 - Esquema da propriedade rural estudada.

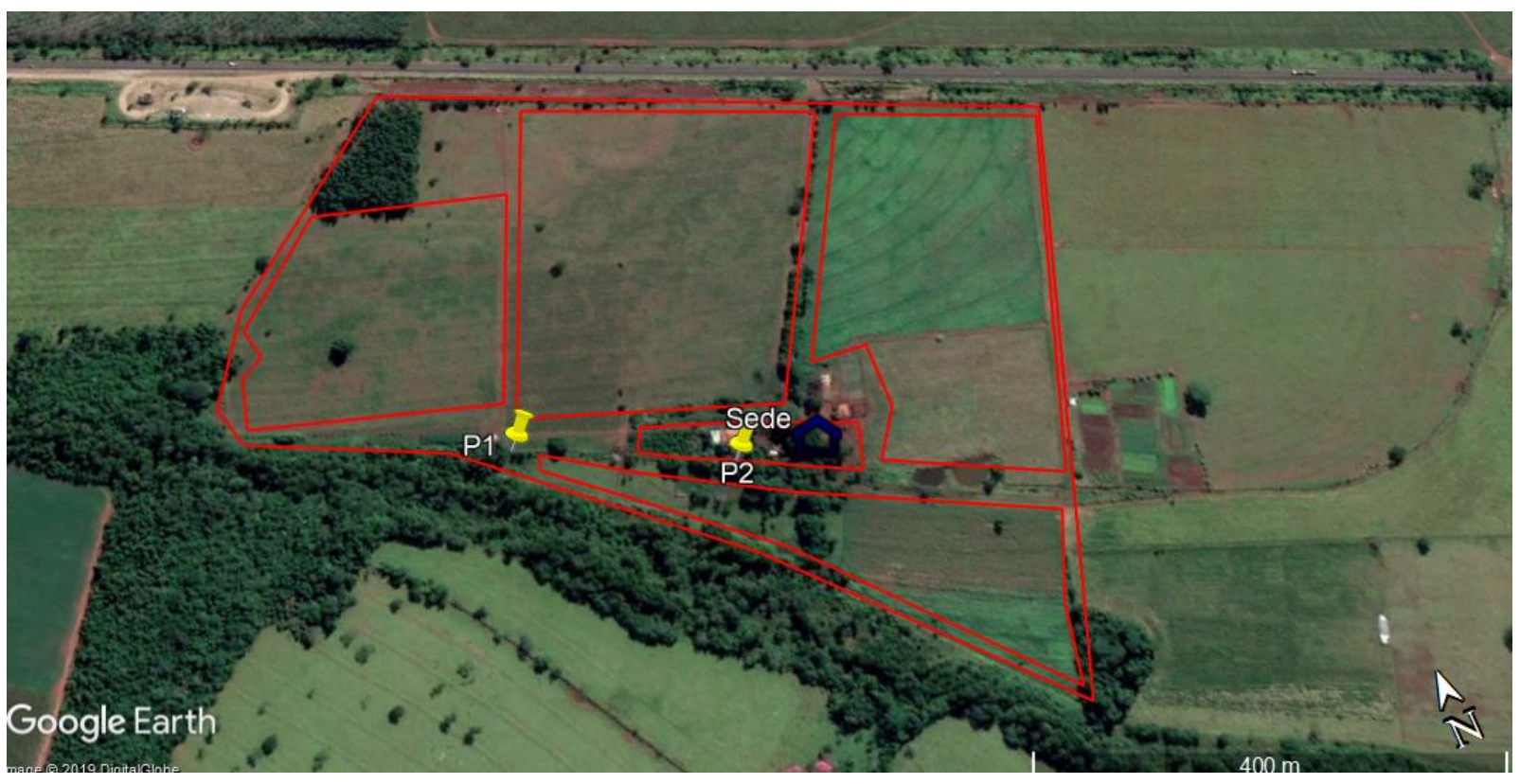

Legenda: $\mathbf{P 1}=$ Antes do contato com o gado e $\mathbf{P 2}=$ Após o contato com o gado.

Fonte: Elaborada pelos autores, com imagens do Google Earth (2019).

Nucleus, v.17, n.1, abr. 2020 


\subsection{Coleta e preparação das amostras}

Foram coletadas 12 amostras ( 2 amostras mensais, durante 6 meses consecutivos) em um rio de primeira ordem que passa por dentro da propriedade rural que está localizada no município de Frutal (MG) e que tem como atividade principal a pecuária leiteira. Foram escolhidos dois pontos de coleta ao longo do córrego (com 235 m de distância entre eles), de onde se utiliza a água para a irrigação de hortaliças. $\mathrm{O}$ ponto $1(\mathrm{P} 1)$ refere-se ao ponto do córrego localizado próximo à sede da propriedade, ponto este onde o gado não possui contato para dessedentação, e o ponto 2 (P2) refere-se ao ponto junto à sede, a cerca de $100 \mathrm{~m}$ de onde o gado tem contato com a água.

\subsection{Variáveis físico-químicas, nutrientes e coliformes termotolerantes}

Em cada ponto amostral foram mensuradas na subsuperfície da água as variáveis temperatura, condutividade elétrica, $\mathrm{pH}$, turbidez, oxigênio dissolvido e sólidos total solúveis utilizando uma sonda multiparâmetros modelo HORIBA U-50.

A amostragem da água para determinação de nutrientes ocorreu em frascos de polietileno previamente limpos/esterilizados com capacidade para armazenamento de $500 \mathrm{~mL}$. Os teores de Fósforo total, nitrato, nitrito e amônia foram determinados através da espectrofotometria de acordo com metodologia descrita por Koroleff (1976) e Golterman; Clymo; Ohnstad (1978). As amostras para a quantificação dos nutrientes foram congeladas imediatamente após as coletas para serem analisadas a posteriori.

Para a determinação de coliformes termotolerantes, as coletas foram realizadas com frascos de vidro previamente esterilizados, posteriormente transportados para o laboratório onde ocorreram as análises. A determinação de coliformes termotolerantes foi feita com meio de cultura A1, a $44,5^{\circ} \mathrm{C}$, em séries múltiplas de 5 tubos de ensaio contendo tubos de Durham, conforme Companhia Ambiental do Estado de São Paulo (CETESB, 2007). Os resultados foram expressos em média de Número Mais Provável (NMP) de coliformes termotolerantes. $100 \mathrm{~mL}^{-1}$ de água e comparados com os limites da legislação (BRASIL, 2005).

Todos os resultados estão expressos pelas médias obtidas nas seis coletas. Para análise estatística dos dados, foram utilizados os testes de Lilliefors e Bartlett e análise de resíduos para verificação da normalidade e homogeneidade das variâncias, ao nível de significância $@=0,05$ dos dados. Para o teste de normalidade positivo, foi aplicado uma análise de variância seguida pelo teste de Fischer, para verificar a diferença entre os pontos. Com a não ocorrência de normalidade dos dados, foi aplicado o teste não paramétrico de Friedman 
(SIEGEL, 1975). Todos os testes foram executados no software Statistica 8.0 (STATSOFT, 2007).

\section{RESULTADO E DISCUSSÃO}

Os resultados mostraram que, em relação aos parâmetros físico-químicos avaliados, o único fora dos padrões da legislação e que sofreu alteração significativa entre os pontos de coleta foi a turbidez. O padrão para turbidez da água é de 100 NTU.100 mL ${ }^{-1}$ e, como pode ser observado, foram encontrados valores médios acima do permitido nas coletas no ponto 2 , indicando que o contato do gado na água aumentou significativamente a quantidade de materiais finos em suspensão na água. Para os outros fatores físico-químicos (condutividade, $\mathrm{pH}$, Oxigênio dissolvido, sólidos solúveis totais e temperatura), os valores estão dentro dos padrões e as variações não foram significativas (Figura 2). 
Figura 2 - Gráficos Boxplot das variáveis físicas e químicas da água onde: quadrados = média; retângulos = erro padrão; barras = desvio padrão.
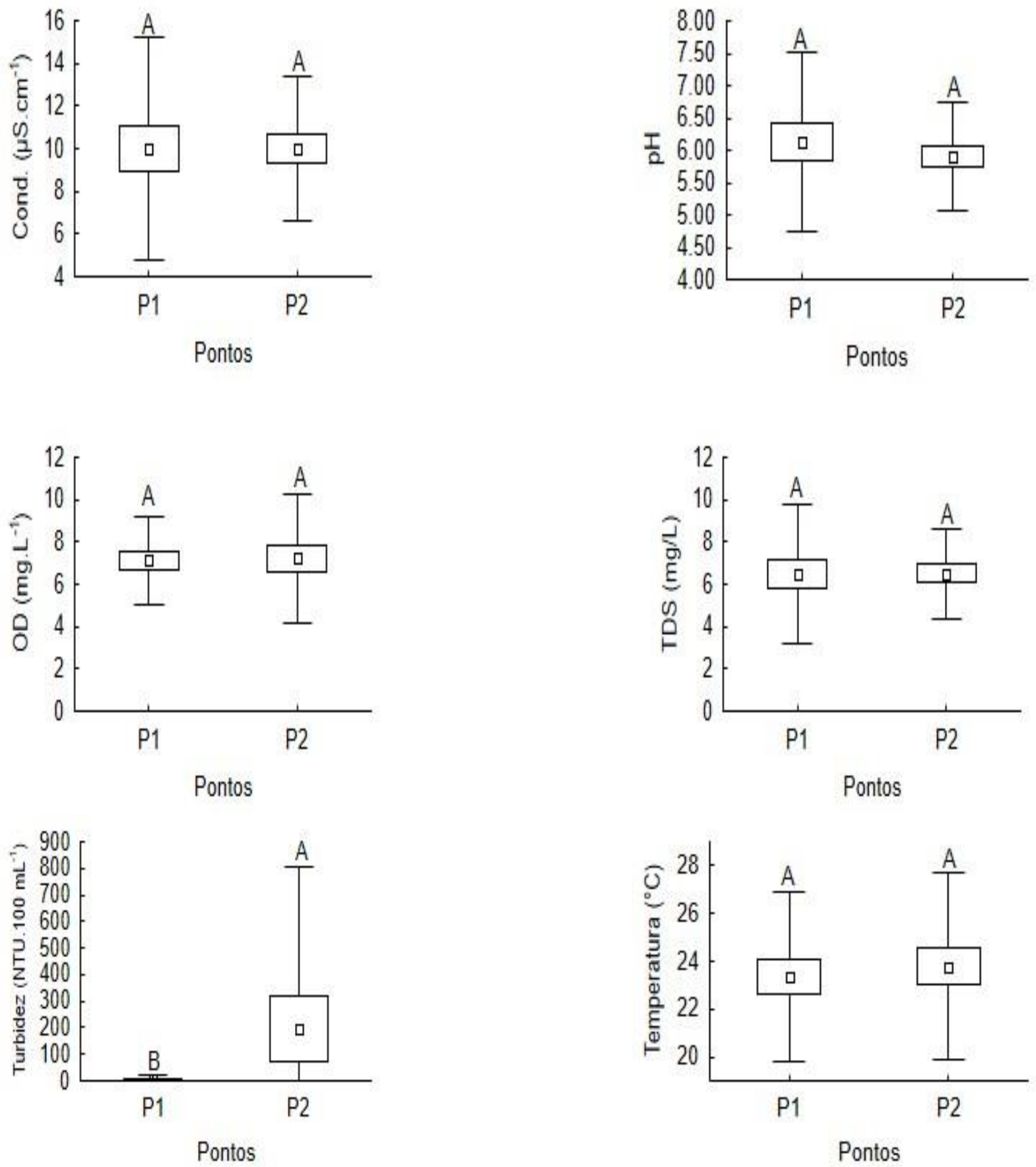

Legenda: Cond.: Condutividade; pH: Potencial Hidrogeniônico; OD: Oxigênio Dissolvido; TDS: Sólidos Totais Solúveis.

Fonte: Elaborada pelos autores. 
A turbidez é processo de dispersão de partículas suspensas em água, esse parâmetro em excesso pode ocasionar a dificuldade da fotossíntese dos organismos aquáticos, pois se a turbidez aumenta, automaticamente a inserção de luz solar no ambiente diminui, fazendo com que a atividade fotossintética diminua, ocasionando desequilíbrios ecológicos (FERREIRA et al., 2015). A variação da turbidez entre os pontos avaliados pode estar diretamente ligada ao fato da transição do gado. Assim, essa parte de transição e contato do gado próximo ao recurso interferiu na qualidade do ambiente aquático.

A temperatura da água variou de 19,2 a $25,7^{\circ} \mathrm{C}$, sendo menores nos meses de inverno (junho setembro) e mais elevadas nos meses da primavera (setembro a novembro), conforme esperado para as estações na região de estudo (Figura 2). Jian, Cheng e Chen (2003) destacam que a temperatura da água é uma variável importante, pois está associada ao consumo de oxigênio, crescimento e sobrevivência dos organismos.

$\mathrm{O}$ pH da água na maioria das coletas apresentou-se ácido, com valores entre 5,8 a 6,4, essa acidez pode estar ligada ao processo de inserção de matéria orgânica no sistema e também pode estar ligada com a presença de compostos químicos que são aplicados no plantio de cana de açúcar que está presente ao redor da área de estudo. $\mathrm{O}$ pH da água é uma das principais variáveis aferidas pois influencia vários processos físicos, químicos e biológicos do solo, estando relacionado à disponibilidade de alguns nutrientes, metais pesados e pesticidas. A respiração, fotossíntese, adubação, calagem e poluição são os cinco principais fatores que afetam os valores de $\mathrm{pH}$ na água (IMBIRIBA, LOURENÇO JÚNIOR, MOURA CARVALHO, 2000; SILVA, FERREIRA, LOGATO, 2003).

Com relação ao oxigênio dissolvido (OD), de acordo com a resolução CONAMA 357/2005 (BRASIL, 2005), o valor de deve ser de no mínimo 5,0 mg. $\mathrm{L}^{-1}$. Foi observado que ambos os pontos estão dentro do padrão, e a média variou entre 7,0 e 8,2 mg. $\mathrm{L}^{-1}$.

Os valores médios de condutividade elétrica da água estão dentro do padrão exigido pela Resolução Conama n 357 de 2005 tendo um valor de $10 \mu{\mathrm{S} . \mathrm{cm}^{-1}}$, indicando pouca decomposição de matéria orgânica (Figura 2). Dados próximos aos do presente estudo foram encontrados por Adrietti et al. (2016), com valores médios variando entre 1 e $19 \mu \mathrm{S} . \mathrm{cm}^{-1}$. Segundo Frota Júnior et al. (2007), a condutividade elétrica é um parâmetro afetado por efeito acumulativo de sais totais na água, como cloretos, carbonatos, fosfatos e sulfetos. Portanto, poder-se-ia esperar resultados superiores, o que não foi observado nas águas deste rio.

Segundo a resolução 357 do CONAMA, o valor máximo de sólidos totais solúveis permitidos ou que ultrapassado indicam a existência de alguma alteração em corpo hídrico é 
$500 \mathrm{mg} \cdot \mathrm{L}^{-1}$. Sendo assim, nos dados coletados observamos que o valor máximo encontrado nos pontos foi de $7 \mathrm{mg} . \mathrm{L}^{-1}$ (figura 2).

Quanto aos nutrientes avaliados, observou-se que o único que estava fora dos padrões da legislação foi o Fósforo total, nos dois pontos avaliados. Como o valor máximo de Fósforo total permitido pela Resolução CONAMA 357 de 2005 é de 30,0 $\mu \mathrm{g} . \mathrm{L}^{-1}$ (BRASIL, 2005), os pontos de coleta apresentaram-se fora dos padrões permitidos, com médias superiores a 100 $\mu g . L^{-1}$ (Figura 3). A presença de fósforo na água pode ser influenciada principalmente pelo tipo de solo e atuação de sistemas agrícolas com incremento de fosfatos.

De acordo com a Resolução CONAMA 357 de 2005 (BRASIL, 2005), os valores permitidos para nitrogênio amoniacal total para águas é de 3700,0 $\mu \mathrm{g} . \mathrm{L}^{-1}$ (com pH inferiores a 7,5 ) e nos dados obtidos observou-se que o valor máximo encontrado (média de 60,0 $\mu \mathrm{g} . \mathrm{L}^{-1}$ ) muito abaixo do limite máximo permitido (Figura 3).

Para o nitrito, o limite da legislação é de 1000,0 $\mu \mathrm{g} \cdot \mathrm{L}^{-1}$, Resolução CONAMA 357 de 2005 (BRASIL, 2005), sendo que o maior valor encontrado foi de cerca de 60,0 $\mu \mathrm{g} . \mathrm{L}^{-1}$ (Figura 3), quase 5 vezes abaixo do limite máximo permitido.

Para nitrato o limite é de $1.0000,0 \mu \mathrm{g} . \mathrm{L}^{-1}$, sendo que o maior valor encontrado neste estudo foi de 70,0 $\mu \mathrm{g} . \mathrm{L}^{-1}$ (Figura 3), cerca de 100 vezes abaixo do permitido pela Resolução CONAMA 357 de 2005 (BRASIL, 2005). Resultados semelhantes foram encontrados no estudo de Molisani et al. (2013), no qual o nitrato apresentou valores baixos. De acordo com os autores, tanto o nitrogênio amoniacal total como o nitrato são perdidos por meio do processo de desnitrificação. 
Figura 3 - Gráficos Boxplot dos nutrientes da água onde: quadrados = média; retângulos = erro padrão; barras $=$ desvio padrão.
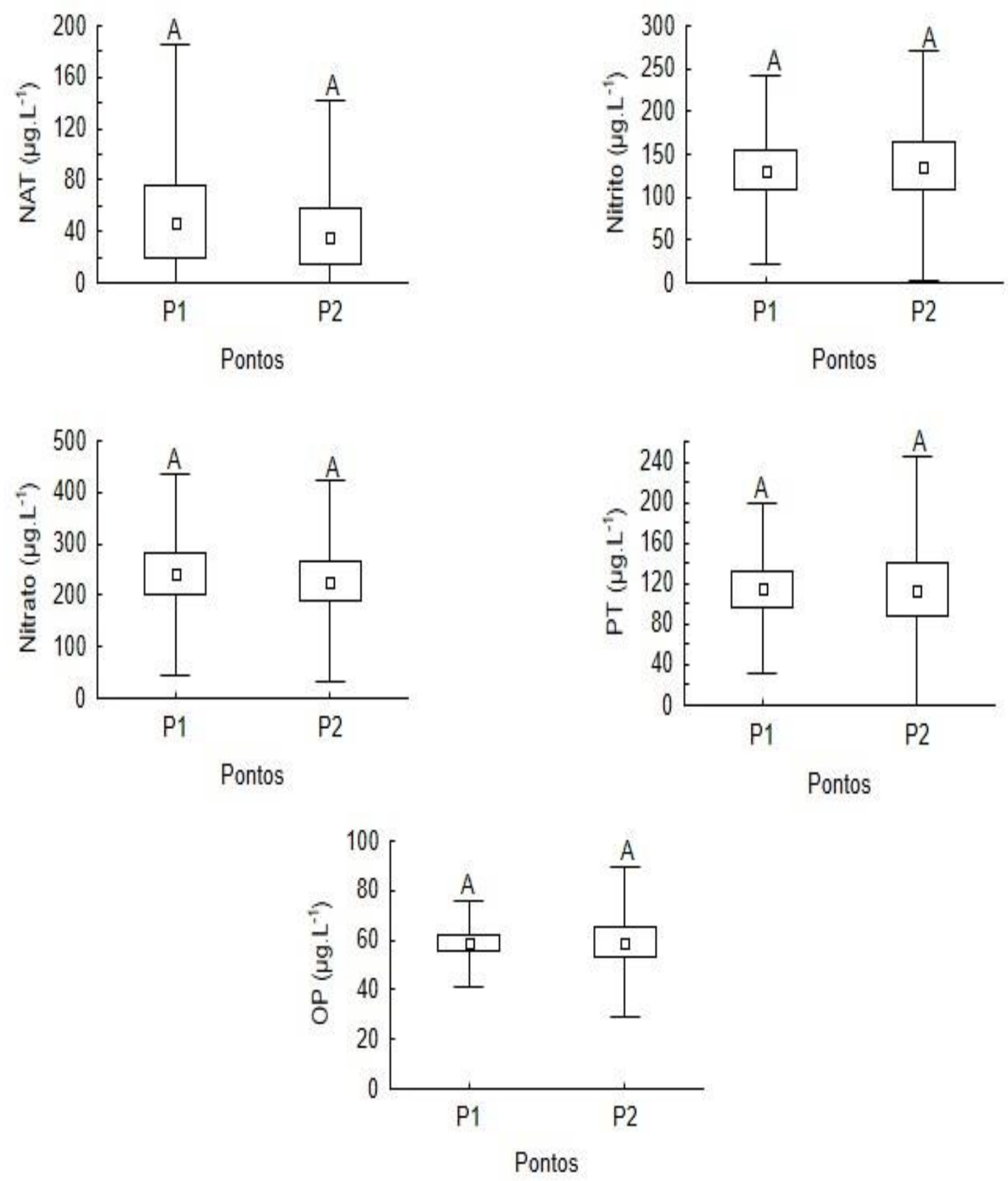

Legenda: NAT: Nitrogênio amoniacal total; PT: Fósforo Total; OP: Ortofosfato.

Fonte: Elaborada pelos autores.

Dentre os nutrientes encontrados dissolvidos na água, os mais importantes para definir padrões de qualidade de água são os compostos fosfatados e nitrogenados. O nitrito e o nitrato estão presentes nas águas e podem ser de origem natural resultante do metabolismo de Nucleus, v.17, n.1, abr. 2020 
microrganismos, ou de origem antrópica devido a vários fatores como, excrementos de animais e fertilizantes. A alta concentração de nitrito e nitrato podem ocasionar a eutrofização dos recursos hídricos gerando o desequilíbrio no meio ambiente aquático e no solo. Estes fatores degradantes são ocasionados pela ação natural ou humana (VON SPERLING, 2007).

O nitrato é a forma de nitrogênio predominante em águas com concentração elevada de oxigênio dissolvido, sendo dependente da atividade biológica e o elemento final da nitrificação (NEOFITOU, KLAOUDATOS, 2008). Porém nos resultados obtidos, ocorreu o inverso, os valores de oxigênio altos em relação à taxa de nitrogênio que está baixa, devendose isso ao intenso fluxo de água.

O parâmetro que mais foi afetado em relação à bovinocultura na propriedade rural foi a concentração de coliformes termotolerantes, com média de mais de 6000 NMP.100.mL ${ }^{-1}$ (Figura 4). O ponto P2 apresentou aumento significativo de coliformes termotolerantes em relação ao ponto $\mathrm{P} 1$, inclusive fazendo com que a água ficasse fora do limite máximo da legislação, que é de 1.000 NMP.100. $\mathrm{mL}^{-1}$ (Figura 4).

Figura 2 - Gráficos Boxplot da variável coliformes termotolerantes (C.T.) da água onde: quadrados = média; retângulos = erro padrão; barras = desvio padrão.

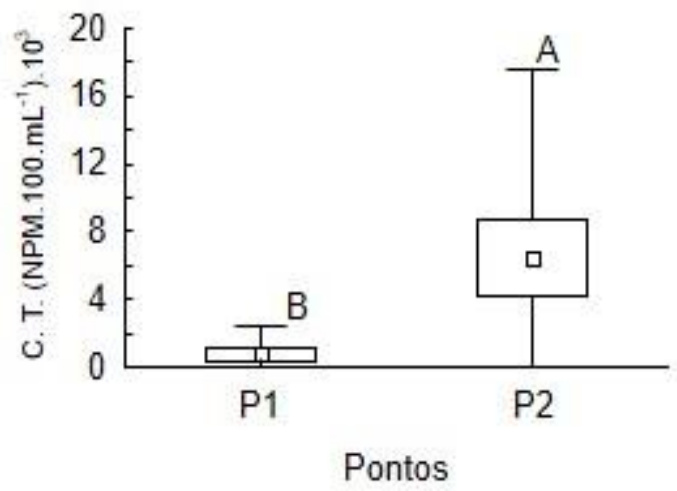

Fonte: Elaborada pelos autores.

No grupo dos coliformes termotolerantes (CTT) estão incluídas as bactérias com as mesmas características dos coliformes totais, mas que continuam a fermentar a lactose na temperatura $45^{\circ} \mathrm{C}$, sendo que $90 \%$ dos CTT encontrados são Escherichia coli (FRANCO, LANDGRAF, 1996).

O aumento de CTT é atribuído ao contato com o gado na água entre os pontos P1 e P2, contaminando ou aumentando a contaminação da água, como detectado no ponto P2. Além do 
contato, também temos as fezes dos animais no ambiente próximo ao rio, quando chove, por processo de lixiviação. Assim, essas fezes vão para o sistema ocasionando contaminação da água.

\section{CONCLUSÃO}

A água avaliada estava dentro dos padrões para a maioria dos parâmetros avaliados. Por outro lado, estava com turbidez mais elevada e concentração muito acima da permitida em relação ao Fósforo Total e aos coliformes termotolerantes. Com relação à elevada turbidez e concentração de coliformes termotolerantes, esses parâmetros apresentaram significativa relação com a presença do gado entre os pontos de coleta. A utilização dessa água leva ao risco de doenças por microrganismos patogênicos presentes e, dessa forma, medidas devem ser tomadas para que as fezes do gado não contaminem os corpos d'água.

\section{AGRADECIMENTOS}

Ao Programa BIC JR UEMG/CNPq/FAPEMIG, pela bolsa de Iniciação Científica concedida.

\section{REFERÊNCIAS}

ANDRIETTI, G.; FREIRE, R.; AMARAL, A. G.; ALMEIDA, F. T.; BONGIOVANI, M. C.; SCHNEIDER, R. M. Índices de qualidade da água e de estado trófico do rio Caiabi, MT. Ambiente \& Água - An Interdisciplinary Journal of Applied Science, Taubaté, v. 11, n. 1, ed. 11, p. 162-175, 2016. Disponível em: <

http://www.scielo.br/pdf/ambiagua/v11n1/1980-993X-ambiagua-11-01-00162.pdf> Acesso em: 12 dez. 2019.

APHA, 2012. Standard Methods for the Examination of Water and Wastewater, 22nd Ed.: American Public Health Association, American Water Works Association, Water Environment Federation. Washington, DC.

BRASIL. Ministério do Meio Ambiente, Conselho Nacional do Meio Ambiente CONAMA. Resolução 357/2005. BRASÍLIA: 2005. Disponível em: < http://www2.mma.gov.br/port/conama/legiabre.cfm?codlegi=459> Acesso em: 10 dez. 2019.

BORTOLI, J.; MACIEL, M. J; SANTANA, E. R. R.; REMPEL, C. Avaliação microbiológica da água em propriedades rurais produtoras de leite localizadas no Rio Grande do Sul, Brasil. Revista Brasileira de Higiene e Sanidade Animal, Fortaleza, v.12, n.1, p. 39-53, 2018. Disponível em:

<http://www.higieneanimal.ufc.br/seer/index.php/higieneanimal/article/view/426> Acesso em: 15 dez. 2019. 
BURGOS, T. N.; SCHUROFF, P. A.; LOPES, A. M.; LIMA, N. R.; PELAYO, J. S. Água de consumo humano proveniente de poços rasos como fator de risco de doenças de veiculação hídrica. Ciência e Saúde, v.16, n. 1, p. 34-38, 2014. Disponível em:

< http://www.periodicoseletronicos.ufma.br/index.php/rcisaude/article/view/3404 > Acesso em: 15 dez. 2019.

CETESB (São Paulo). L5. 406: Coliformes termotolerantes: determinação em amostras ambientais pela técnica de tubos múltiplos com meio A1 - método de ensaio. São Paulo, 2007.

FERREIRA, A. C.; ROCHA, L. C.; FIGUEIREDO, M. do A. Análise do índice de qualidade de água na bacia do Córrego do Rio Acima, São João Del Rei/MG. Rev. Nacional de Gerenciamento de Cidades, v. 03, n. 15, p. 94-105, 2015. Disponível em: < https://www.amigosdanatureza.org.br/publicacoes/index.php/gerenciamento_de_cidades/articl e/view/994/0> Acesso em: 19 dez. 2019

FRANCO, B. D. G. M; LANDGRAF, M. Microbiologia de alimentos. São Paulo: Atheneu, 1996, 182p.

FROTA JÚNIOR, J. I.; ANDRADE, E. M.; MEIRELES, A. C. M.; BEZERRA, A. M. E.; SOUZA, B. F. S. Influência antrópica na adição de sais no trecho perenizado da bacia hidrográfica do Curu, Ceará. Revista Ciência Agronômica, v. 38, p. 142-148, 2007. Disponível em: < http://ccarevista.ufc.br/seer/index.php/ccarevista/article/view/126> Acesso em: 18 dez. 2019.

GOLTERMAN, H. L.; CLYMO, R. S.; OHNSTAD, M. A. M. Methods for physical and chemical analisys of freshwater. Oxford: Blackwell Scientific Publications, 1978. 213 p.

GROTT, S. C.; HARTMANN, B.; SILVA FILHO, H. H.; FRANCO, R. M. B., GOULART, J. A. G. Detecção de cistos de Giardia spp. e oocistos de Cryptosporidium spp. na água bruta das estações de tratamento no município de Blumenau, SC, Brasil. Revista Ambiente \& Água, v. 11, p. 689-701, 2016. Disponível em: < http://www.scielo.br/scielo.php?pid=S1980993X2016000300689\&script=sci_abstract\&tlng=pt $>$ Acesso em: 20 dez. 2019.

IMBIRIBA, E. P.; LOURENÇO JÚNIOR, J. de B.; MOURA CARVALHO, L. O. D. de. Parâmetros ambientais e qualidade de água na piscicultura. Belém: Embrapa Amazônia Oriental, 2000. 4 p. (Embrapa Amazônia Oriental. Recomendações Técnicas, 8). Disponível em: < https://www.embrapa.br/busca-de-publicacoes/-/publicacao/377896/parametrosambientais-e-qualidade-da-agua-na-piscicultura> Acesso em 20 dez. 2019.

JIAN C.Y; CHENG, S.Y.; CHEN, J. C. Temperature and salinity tolerances of yellowfin sea bream, Acanthopagrus lotus, at different salinity and temperature levels. Aquaculture

Research, v. 34, p. 175-185, 2003.

KASELANI, K. Qualidade da água no meio rural. Veterinária Notícias, v. 23, p. 80-112, 2017. Disponível em: < http://www.seer.ufu.br/index.php/vetnot/article/view/33345> Acesso em 18 dez. 2019.

KOROLEFF, F. Determination of nutrients. In: Grashof, E. \& Kremling E. (eds). Methods of seawater analysis. New York: Verlag Chemie Wenhein, p. 117-181, 1976. 
MOLISANI, M.M.; ESTEVES, F.A.; LACERDA, L.D.; REZENDE, C.E. Emissões naturais e antrópicas de nitrogênio, fósforo e metais para a bacia do rio Macaé (Macaé, RJ, Brasil) sob influência das atividades de exploração de petróleo e gás na bacia de Campos. Química Nova, v. 36, n. 1, p. 27-33, 2013. Disponível em: < http://www.scielo.br/pdf/qn/v36n1/v36n1a06.pdf> Acesso em: 20 dez. 2019.

NEOFITOU, N.; KLAOUDATOS, S. Effect of fish farming on the water column nutrient concentration in a semi-enclosed gulf of the eastern Mediterranean. Aquaculture Research, v. 39, no. 5, p. 482-490, 2008.

SCURACCHIO, P. A. Qualidade da água utilizada para consumo em escolas no município de São Carlos-SP. 2010. 57 p. Dissertação (Mestrado). Universidade Estadual Paulista. Araraquara. 2013. Disponível em: < https://www2.fcfar.unesp.br/Home/Posgraduacao/AlimentoseNutricao/PaolaAndressaScuracchioME.pdf> Acesso em: 21 dez. 2019.

SILVA, R. C. A.; ARAUJO, T. M. Qualidade da água do manancial subterrâneo em áreas urbanas de Feira de Santana (BA). Ciênc. Saúde Coletiva, v.8, n.4, p. 1019-1028, 2008. Disponível em: < http://www.scielo.br/pdf/csc/v8n4/a23v8n4.pdf> Acesso em: 20 dez. 2019.

SILVA, V. K; FERREIRA, M. W.; LOGATO, P. R. V. Qualidade da água na piscicultura. 2003. (Desenvolvimento de material didático ou instrucional - Extensão). Disponível em: < http://www.editora.ufla.br/index.php/component/phocadownload/category/56-boletins-deextensao?download=1164:boletinsextensao $>$ Acesso em: $18 \mathrm{dez} .2019$.

TIECHER, T. Manejo e conservação do solo e da água em pequenas propriedades rurais no sul do Brasil: práticas alternativas de manejo visando a conservação do solo e da água. UFRGS, Porto Alegre, 186 p., 2017. Disponível em: < http://www.agrisus.org.br/arquivos/livro_RGS.pdf> Acesso em: 12 jan. 2020.

VALIAS, A.P.G.S et al. Avaliação da qualidade microbiológica de águas de poços rasos e de nascentes de propriedades rurais do município de São João da Boa Vista-SP. Arq. Ciên. Vet. Zool, v. 5, n. 1, 2002. Disponível em:

<https://revistas.unipar.br/index.php/veterinaria/article/view/742/649> Acesso em: $12 \mathrm{dez}$. 2019.

VON SPERLING, M. Estudos e modelagem da qualidade da água de rios: princípios do tratamento biológico de águas residuárias. UFMG, Belo Horizonte, 588 p., 2007. 